\title{
RESEÑA: VIRGINA WOOLF Y EL HELENISMO, 1897-1925. LUCÍA P. ROMERO MARISCAL ${ }^{1}$

\author{
Pedro Jesús Molina Muñoz ${ }^{2}$
}

\begin{abstract}
Lucía P. Romero Mariscal, Virginia Woolf y el Helenismo, 1897-1925. Valencia: Alfons el Magnànim, 2012. ISBN 978-84-7822-621-4.
\end{abstract}

La relación de Virginia Woolf con la lengua y literatura griegas ha sido poco estudiada incluso fuera de España y es, desde luego, prácticamente desconocida para el público hispanohablante. El primer mérito de este libro es el de haber perseguido con detalle muy minucioso esa relación, cotidiana primero, asidua y esforzada después, de la escritora inglesa con el griego, como lengua que da acceso a una literatura extraordinaria, y con una particular idea de Grecia, que debe leerse sobre el trasfondo del papel que Grecia ha jugado en la cultura inglesa desde el siglo XIX hasta nuestros días.

Un segundo mérito del libro es el de haber puesto de relieve el alcance de la dedicación de Virginia Woolf a una lengua que le era a la vez tan próxima y tan extraña. En efecto, el estudio de la lengua griega era en la época de Virginia Woolf el privilegio casi exclusivo de una elite intelectual y académica masculina, contra la que suele arremeter la propia Woolf en su obra, de modo que su apropiación del griego no solamente constituirá la base necesaria para cumplir, de manera similar a la de los hombres, su propia formación como escritora, sino que es capaz de transformar ese privilegio en un don al lector común. De este modo, leer en griego se convertirá en la piedra angular de su formación como intelectual que aprende, además, a través de las primeras académicas dedicadas profesionalmente a la lengua y cultura griegas, como la famosa Jane Harrison y, sobre todo, como su profesora particular, Janet Case.

\footnotetext{
${ }^{1}$ Fecha de recepción: 03/09/2013

Fecha de aceptación: 05/09/2013

${ }^{2}$ Special Scientist, Spanish Section, Language Center, University of Cyprus, Nicosia, Cipre; $\square$ munoz. molina@ucy.ac.cy.
} 
De la lectura del libro de Lucía P. Romero Mariscal (LPRM en lo sucesivo) se desprende una conclusión que puede sorprender en principio. La lengua griega aparece íntimamente relacionada no ya con el feminismo de Virginia Woolf, sino con el feminismo tout court. Sus primeras lecciones las recibe del catedrático de literatura griega del King's College de Londres, el profesor Warr, cuyo compromiso con la formación académica de las mujeres fue de un extraordinario valor en su época. También Clara Pater, la hermana del reconocido Walter Pater, contribuyó al aprendizaje del griego de Virginia Woolf, quien la recordará no solamente en sus cartas y diarios, sino, además, en algunas de sus obras literarias, especialmente en el relato titulado "Momentos de Vida: Los alfileres de Slater no tienen punta". Finalmente, la influencia de Janet Case, la primera mujer que participó en una representación teatral de las "obras griegas" de Cambridge y una de las primeras licenciadas del Girton College, será extraordinaria en la escritura y la vida de Virginia Woolf.

Los capítulos de la obra siguen un orden biográfico que nos permite asistir, día a día como si dijéramos, al proceso de aprendizaje y a la maduración de sus frutos. Este es, en nuestra opinión, el tercer mérito de la obra, pues el resultado es una lectura muy amena. En el primer capítulo LPRM sigue la evolución desde las primeras lecciones de griego en 1897 hasta la consagración como escritora de Virginia Woolf en 1925. El material consultado es muy abundante: la edición de los diarios personales, del epistolario de la autora, de sus notas de cuadernos de lectura, así como de sus primeros ensayos, relatos y novelas. La información que se extrae de estas fuentes primarias de consulta, que se citan en lengua original y en traducción, es igualmente rica y reveladora del empeño apenas sin desmayo de Virginia Woolf en hacerse con la lengua y la literatura griegas, sobre las que vuelve constantemente con esfuerzo y devoción. LPRM subraya que, en la mayoría de las ocasiones, la joven escritora manifiesta un cuidado casi filológico, y hace explícita la consulta, el estudio, la lectura o las referencias a obras y autores de la Antigüedad. En otras ocasiones, sus estrategias son más indirectas, sus alusiones más refinadas y sutiles, también más eruditas o irónicas, hasta el punto de pasar desapercibidas a un lector no familiarizado con la filología clásica, i. e. no tan común como Virginia Woolf quiso hacernos creer. 
El segundo capítulo está dedicado a la idea de Grecia de la escritora, una idea que incorpora al griego de cada día la experiencia del viaje a Grecia, elevado por la cultura inglesa a la condición de iniciático. LPRM describe y analiza el primer viaje a Grecia que Virginia realizara en 1906 en compañía de sus hermanos Thoby y Adrian, de su hermana Vanessa y de su entrañable amiga Violet Dickinson. Este viaje encontrará sus prefiguraciones literarias en un relato breve, probablemente escrito por esas mismas fechas, titulado "Un diálogo en el monte Pentélico”, así como en la que será su primera novela "modernista", El cuarto de Jacob, publicada en 1922. En todos estos ejemplos se contrapone la Grecia idealizada por la "inteligencia" masculina a la Grecia dividida entre el ideal y la realidad en la visión femenina de la autora, de la voz narradora, y de los personajes femeninos.

El tercer y último capítulo regresa a la lengua griega y la literatura escrita en esa lengua de tan extrañas virtudes. En él son objeto de detallado estudio dos ensayos publicados por Virginia Woolf y centrados exclusivamente en el griego: "La lengua perfecta", de 1917, y "Del no saber griego", ensayo este último publicado dentro de la colección titulada El lector común y publicada en 1925. En estos ensayos la escritora destaca la belleza inaprehensible de la lengua griega, su irresistible atractivo incluso para quienes, como ella, se sienten excluidas debido a sus limitaciones en una formación no especializada. La dificultad del griego es una dificultad intrínseca, por otra parte, a la de una lengua arcana y misteriosa como todo lo antiguo y ya perdido. Pero esta lengua ha dado, para la escritora y lectora ávida, una literatura que está a salvo del tiempo.

El libro de LPRM constituye a nuestro juicio una muy importante aportación a tres campos de estudio. Es, en primer lugar, una contribución especialmente valiosa a los conocidos como Reception Studies, aplicados a una autora excepcional cuya vinculación a la literatura clásica ha sido con frecuencia considerada como una inclinación curiosa, pero secundaria. Los estudios de género tienen también en el libro una aportación a una autora emblemática y de ideas disputadas sobre la condición de la mujer y de su oficio de escritora. Y las personas que aman la literatura de Virginia Woolf tienen perspectivas inusitadas para mirar el mundo desde el sillón de la escritora 